\title{
Terrorism, Tourism and Economic Growth: A Vector Autoregression (VAR) Analysis
}

\author{
Ismail Ademola Oyetunde ${ }^{1 *}$ and Rafiu Olayinka Akano ${ }^{2}$ \\ ${ }^{1,2}$ Department of Statistics, University of Abuja, Abuja, Nigeria. \\ "Corresponding Author: oyetundeismail@gmail.com
}

Received: $16^{\text {th }}$ June 2018 / Revised: $25^{\text {th }}$ September 2019 / Published: $31^{\text {st }}$ December 2019

CIAppstat-SL2019

\begin{abstract}
This research paper is design to investigate the dynamics of interrelationships between/among Terrorism, Tourism, and GDP growth in Nigeria. This study used number of terrorist attack, and number of international tourist arrivals as proxy for Terrorism and Tourism respectively. Time series techniques including Unit Root Test, VAR test for serial correlation and ARCH, CUSUM test for stability, Impulse Response Function were used with data from $1^{\text {st }}$ Quarter 1981 to $4^{\text {th }}$ Quarter 2013. The results of the unit root tests are reported in Table 2. The results indicate that Terrorism, Tourism, and GDP growth are stationary at level. The CUSUM-test showed that all the residuals are stable over long run coefficient and short run dynamics. The results indicate the absence of any instability of the coefficients because the plots of the CUSUM statistics fall inside the critical bands of the 5\% confidence intervals of parameter stability. The Impulse Response Function analysis showed that an innovation into terrorism tends to decrease in GDP growth. Thus, there is an urgent need for the government to stop the activities of the terrorists if Nigeria is to promote her economic growth.
\end{abstract}

Keywords: Terrorism, Tourism, GDP growth, Time Series, Vector Autoregression, Impulse Response Function.

\section{Introduction}

The events of 9/11 in the US served to draw the attention of many to terrorism globally; terrorism has had a long history in Africa; from the Sherifian dynasty of the Alawites and Filali in Morocco to the Regencies in Algeria, Tunisia and Libya 
under the effete suzerainty of the Sultan of Turkey. The Berber-Arab population in North Africa has experienced one form of terrorism to another, even before colonial rule; among them was the French invasion of Algeria in 1830, the establishment of French rule in Morocco in the 1900s, all these and many more were characterized as a terrorist act. The journeys of independence in most countries of Africa were also strewn with one act of terrorism to another. For instance, in East Africa, especially in Kenya, Tanzania, and Uganda, international terrorism coalesced in the bombing of US embassies in 1997 (Barash and Webel, 2002).

Since the increase in proportion of kidnapping and blasting of oil pipelines in the Niger Delta, the number of international investors coming to Nigeria has reduced drastically while some foreign companies who had been in Nigeria for several years before the terrorist activities began have relocated to other neighboring countries such as Ghana, Togo and South Africa where they were sure to enjoy relative peace, security and supply of electricity.

Tourism is considered as one of the world largest growing industry and despite the occurrences of terrorism, air catastrophes, tsunamis and other natural disasters and even the present global economic meltdown, it has remained robust as there is no sign of slowing down in growth trend. In today's challenging economic climate, every business needs an organization-wide commitment to a comprehensive marketing strategy so it will stand out among the growing number of competitors competing for consumers (Iyiola and Oni-Ojo, 2013); however, tourism business in Nigeria has failed to do this. Despite many obstacles facing the continent of Africa, tourism is having an impact on the economy of the continent.

According to (WTO, 2009) international tourist arrivals have continued to experience a growth trend from 25 million in 1950, to 277 million in 1980, to 438 million in 1990, to 684 million in 2000, and reaching 922 million in 2008. The robust growth market for tourism has been in Africa, with most destinations showing steadily more than above average increases in arrivals and receipts. For example, from 2000 and 2005, international tourist arrivals to Africa increased from 28 to 40 million - an average growth of $5.6 \%$ a year, compared to a worldwide ANNUAL total of $3.1 \%$. During this period total Africa's International tourism incomes jumped from US\$ 10.5 billion to US\$21.3 billion (WTO, 2013).

For every economy to have increase in gross domestic product (GDP), tourism remained a significant contributor to economic growth and development globally. It was however un-debatable that the growth in international tourist arrivals could outpace national economic output of some economies with the help of up-to date data. Record has it that there was continuous growth in the tourism sector, with one billion tourists having travelled the world in 2012, marking the tourism sector 
accounts for one in every 12 jobs and $30 \%$ of the world's services exports; but, destinations that developed an unsafe reputation could be substituted by alternative destinations or cities that were perceived as safer and peaceful for tourists; an act of terrorism committed against the tourism sector damages the destination or city image and instilling fear in potential tourists (Bhajwati, 1998; ITAC, 2006). The aim of this study is to make a VAR analysis of dynamic interrelationships between/among Terrorism, Tourism and GDP growth in Nigeria.

\subsection{Research Problem}

Nigeria is a developing country and it is after its freedom trying her best to grow its economy in every section. Like all other industries, Nigeria tourism industry is in growth stage and there is a need to promote Nigeria as a tourist destination but since last few years' tourism industry had to suffer a lot and terrorism is a major factor causing the fall of tourism industry in Nigeria. Terrorism has gradually affected the economy of whole world but developed countries are more strengthen to recover it back but countries like Nigeria needs extra steps to take to get back on the track (GTIR, 26 Sep 2014). According to Koroma (2011), to completely eradicate terrorism is physically impossible. Terrorism just like any other crime committed, steps are taken to prevent the crime from occurring but there are not enough resources such as funds and manpower to eliminate terrorist threats completely. However, it is necessary to bring into attention the interrelationship among terrorism, tourism and economic growth. Despite the increase in research on the causal relationship between tourism and economic growth, terrorism and tourism as well as terrorism and economic growth, no study has been carried out on the interrelationships between terrorism, tourism and economic growth. Thus, there is a need for more research which has potential to help determine the interrelationships between these variables.

\subsection{Aim and Objectives of Study}

It has to be admitted that there are insufficient data on the contribution of tourism to Nigeria's GDP growth. Part of this initiative is to properly situate the contribution of tourism to sustainable development in Nigeria. The study also sets out to clearly and objectively state the potentials and problems of the Nigerian tourism industry, terrorist attacks and identify the solutions. The purpose of this study is to investigate the dynamics of interrelationships between/among Terrorism, Tourism, and GDP growth in Nigeria. 


\section{Literature Review}

There seems to be a consensus among scholars on the negative impacts that terrorism is having on the global tourism industry. (Wahab, 1995; Abraham and Yoel, 1996; Adam and Sinclair, 2002), Wahab (1995) opined that random acts of terrorism curtail travel activities and may remain so until the public memories of the publicized incidents fade. Adam and Sinclair (2002) who studied the negative effects of the September 2001 al Qaeda air strikes on the US were of the opinion that the repercussions of the strikes extended beyond the activities that were directly associated with tourism. Essner (2003) reported that Kenyan economy lost a whopping $12 \%$ of annual gross domestic product (GDP) which is tourism driven due to the bombing of the U.S. embassy in Nairobi in 1998, and a beach hotel in Mombasa in 2002.

In the analysis of tourism, economists emphasize the economic effects of tourism development on the economy. Because tourism is a multidisciplinary activity that involves several industries and draws upon a variety of skills, its benefits are spread over a wider section of society comparatively to other sectors of the economy (Telce and Schroenn, 2006). Pioneering studies from (Lea and Sinclair, 1998) have highlighted the potential effect of the tourism industry in promoting growth, creating jobs and generating revenue for the government. This economic relationship is known as Tourism Led-Growth hypothesis. According to this hypothesis, the international tourism is considered as a potential strategic factor for economic growth (Sinclair and Stabler, 2002); so that, tourist spending, as an alternative form of exports, provides the foreign exchange earnings. Subsequently, it is used to import capital goods to produce goods and services, which in turn leads to economic growth in host countries (McKinnon, 1964, Balaguer and Cantavella, 2002). On the other hand, international tourism would contribute to an income increase at least in two additional ways: first, enhancing efficiency through increased competition among firms and others international tourist destinations (Krueger, 1980) and second, facilitating the exploitation of economies of scale in local firms (Helpman and Krugman, 1985).

Furthermore, there is a belief that tourism industry development lead to benefit poor people in particular, introducing the concept of "pro-poor tourism" (Ashley and Mitchell, 2006). Thus, the tourism industry may contribute significantly in economic growth, employment and reduction of poverty. In particular, the countries that suffers from high rates of unemployment, low levels of per capita GDP and from the exported products facing difficulties in competing internationally (Archer and Fletcher, 1996 and Durbarry, 2002). 


\section{Data and Methodology}

\subsection{Data}

For the analysis, I use the quarterly time series data for the period of $1^{\text {st }}$ Quarter 1981 to $4^{\text {th }}$ Quarter 2013. The data were sourced from the World Terrorism Database website, World Tourism Organization website, and Nigeria Bureau of Statistics website.

GDP growths are measured in Billion Naira. I use Terrorism as proxy for number of terrorist attack and Tourism as a proxy for number of international tourist arrivals.

\subsection{Model Specification}

The vector autoregressive (VAR) model is one of the most successful, flexible, and easy to use models for the analysis of multivariate time series. It is a natural extension of the univariate autoregressive model to dynamic multivariate time series. The VAR model has proven to be especially useful for describing the dynamic behavior of terrorism, tourism and GDP growth time series and for forecasting.

Let $Y_{t}=\left(y_{1 t}, y_{2 t}, \ldots, y_{n t}\right)^{\prime}$ denote an $(\mathrm{n} \times 1)$ vector of time series variables. The basic $p$-lag vector autoregressive $\operatorname{VAR}(p)$ model has the form:

$$
\begin{gathered}
Y_{t}=c+\Pi_{1} Y_{t-1}+\Pi_{2} Y_{t-2}+\cdots+\Pi_{p} Y_{t-p}+\varepsilon_{t}, t=1,2, \ldots T \\
\varepsilon_{t} \sim N\left(0, \sigma^{2}\right)
\end{gathered}
$$

where $\pi_{i}$ are (n x 1) coefficient matrices and $\varepsilon_{t}$ is an (n $\mathrm{x} 1$ ) unobservable zero mean white noise vector process (serially uncorrelated or independent) with time invariant covariance matrix $\sum$.

For example, a bivariate $\operatorname{VAR}(2)$ model equation by equation has the form

$$
\begin{aligned}
& y_{1 t}=c_{1}+\Pi^{1}{ }_{11} y_{1 t-1}+\Pi_{12}^{1} y_{2 t-1}+\Pi^{2}{ }_{11} y_{1 t-2}+\Pi^{2}{ }_{12} y_{2 t-2}+\varepsilon_{1 t} \\
& y_{2 t}=c_{2}+\Pi^{1}{ }_{21} y_{1 t-1}+\Pi^{1}{ }_{22} y_{2 t-1}+\Pi^{2}{ }_{21} y_{1 t-2}+\Pi^{2}{ }_{22} y_{2 t-2}+\varepsilon_{2 t}
\end{aligned}
$$

where $\operatorname{cov}\left(\varepsilon_{1 t}, \varepsilon_{2 t}\right)=\sigma_{12}$ for $t \neq s ; 0$ otherwise. Notice that each equation has the same regressors-lagged value of $y_{1 t}$ and $y_{2 t}$. Hence, the $\operatorname{VAR}(p)$ model is just a seemingly unrelated regression (SUR) model with lagged variables and deterministic terms as common regressors.

In lag operator notation, the $\operatorname{VAR}(p)$ is written as: 
Terrorism, Tourism and Economic Growth: Vector Autoregression (VAR) Analysis

$$
\Pi(L)=Y_{t}=C+\varepsilon_{t}
$$

where;

$$
\Pi(L)=I_{n}-\Pi_{1} L-\cdots-\Pi_{p} L^{p}
$$

The VAR $(p)$ is stable if the roots of $\operatorname{det}\left(I_{n}-\Pi_{1} Z-\cdots-\Pi_{p} Z^{p}\right)=0$ lie outside the complex unit root circle (have modulus greater than one), or, equivalently, if the eigenvalues of the comparison matrix:

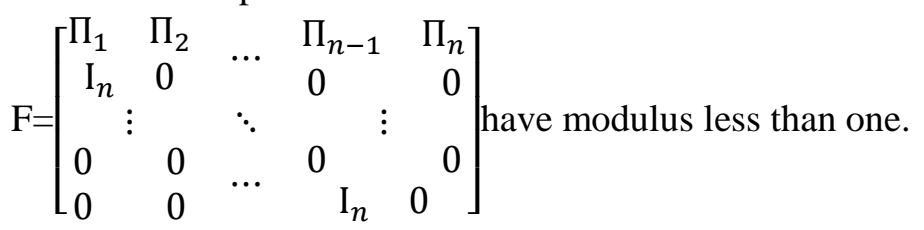

Assuming that the process has been initialized in the infinite past, then a stable $\operatorname{VAR}(p)$ process is stationary and ergodic with time univariate means, variances and autocovariances.

If $Y_{t}$ in (3.1) is covariance stationary, then the conditional mean is given by:

$$
\mu=\left(I_{n}-\Pi_{1}-\cdots-\Pi_{p}\right)^{-1} c
$$

The mean-adjusted form of the $\operatorname{VAR}(p)$ is then:

$$
\left(Y_{t}-\mu\right)=\Pi_{1}\left(Y_{t-1}-\mu\right)+\Pi_{2}\left(Y_{t-2}-\mu\right)+\cdots+\Pi_{p}\left(Y_{t-p}-\mu\right)+\varepsilon_{t}
$$

The basic $V A R(p)$ model may be too restrictive to represent sufficiently the main characteristic of the data. In particular, others deterministic term such as a linear trend or seasonal dummy variables may be required to represent the data properly. Additionally, stochastic exogenous variables may be required as well. The general form of the $\operatorname{VAR}(p)$ model with deterministic terms and exogenous variables is given by:

$$
Y_{t}=\Pi_{1} Y_{t-1}+\Pi_{2} Y_{t-2}+\cdots+\Pi_{p} Y_{t-p}+\Phi D_{t}+G X_{t}+\varepsilon_{t}
$$

Where $D_{t}$ represents an (n x 1) matrix of deterministic components, $X_{t}$ represents an ( $\mathrm{m} \times 1)$ matrix of exogenous variables, and $\Phi$ and $G$ are parameters matrices.

\subsection{Estimation Procedure}

Consider the basic VAR $(p)$ model in (3.1). Assume that the VAR $(p)$ model iscovariance stationary and there are no restrictions on the parameters of the model. In SUR notation, each equation in the $V A R(p)$ may be written as:

$$
y_{i}=Z \Pi_{i}+e_{i}, i=1, \ldots, n
$$


where $y_{i}$ is a ( $\left.\mathrm{T} \times 1\right)$ vector of observations on the $\mathrm{i}^{\text {th }}$ equation, $z$ is a $(\mathrm{T} \times \mathrm{k})$ matrix with $\mathrm{t}^{\text {th }}$ row given by $Z^{\prime}{ }_{t}=\left(1, Y_{t-1}{ }^{\prime}, Y_{t-2}{ }^{\prime}, \ldots, Y_{t-p}{ }^{\prime}\right), k=n p+1, \Pi_{i}$ is $(\mathrm{k} \mathrm{x} 1)$ vector of parameter and $e_{i}$ is a ( $\left.\mathrm{T} \times 1\right)$ error with covariance matrix $\sigma^{2}{ }_{i} I_{T}$.

Since the VAR(p) is in the form of a SUR model where each equation has the same explanatory variables, each equation may be estimated separately by Ordinary Least Squares without losing efficiency relative to generalized least squares.

Let $\widehat{\Pi}=\left[\widehat{\Pi}_{1}, \widehat{\Pi}_{2}, \ldots, \widehat{\Pi}_{p}\right]$ denote the ( $\left.\mathrm{kx} \mathrm{n}\right)$ matrix $\widehat{\Pi}$ into a long (nk x 1$)$ vector.

That is,

$$
\operatorname{Vec}(\widehat{\Pi})=\left(\begin{array}{c}
\widehat{\Pi}_{1} \\
\vdots \\
\widehat{\Pi}_{p}
\end{array}\right)
$$

Under standard assumptions regarding the behavior of stationary and ergodic $V A R$ models $\operatorname{Vec}(\widehat{\Pi})$ is consistent and asymptotically normally distributed with asymptotic covariance matrix.

$\widehat{\operatorname{avar}}(\operatorname{vec}(\widehat{\Pi}))=\Sigma \otimes\left(z^{\prime} z\right)^{-1}$

where:

and

$$
\widehat{\Sigma}=\frac{1}{T-K} \sum_{t=1}^{T} \hat{\varepsilon}_{t} \hat{\varepsilon}_{t}^{\prime}
$$

$\hat{\varepsilon}_{t}=Y_{t}-\widehat{\Pi}^{\prime} z_{t}$ is the multivariate least squares residual from 3.1 at time $t$

The lag length for the $\operatorname{VAR}(p)$ model may be determined using model selection criteria. The general approach is to fit $\operatorname{VAR}(p)$ models with orders $\mathrm{p}=0,1, \ldots, \mathrm{p}_{\max }$ and choose the value of $\mathrm{p}$ which minimizes some model selection criteria. Model selection criteria for $\operatorname{VAR}(p)$ models have the form:

$$
\mathrm{IC}_{(\mathrm{p})}=\ln |\widehat{\Sigma}(p)|+C_{T} \cdot \varphi(n, p)
$$

where $\widehat{\Sigma}(p)=T^{-1} \sum_{t=1}^{T} \hat{\varepsilon}_{t} \hat{\varepsilon}_{t}{ }^{\prime}$ is the residual covariance matrix without a degrees of freedom correction from a $\operatorname{VAR}(p)$ model, $\mathrm{C}_{\mathrm{T}}$ is a sequence indexed by the sample size $\mathrm{T}$, and $\varphi(n, p)$ is a penalty function which penalizes large $\operatorname{VAR}_{(\mathrm{p})}$ models.

The four most common Information Criteria are the Akaike (AIC), SchwarzBayesian (BIC), Hannan-Quinn (HQ) and Final Prediction Error (FPE).

$$
\mathrm{AIC}=\ln |\widehat{\Sigma}(p)|+\frac{2}{T} p n^{2}
$$


Terrorism, Tourism and Economic Growth: Vector Autoregression (VAR) Analysis

$$
\begin{aligned}
& \mathrm{BIC}=\ln |\widehat{\Sigma}(p)|+\frac{\ln T}{T} p n^{2} \\
& \mathrm{HQ}=\ln |\hat{\Sigma}(p)|+\frac{2 \ln \ln T}{T} p n^{2} \\
& \mathrm{FPE}=\ln |\hat{\Sigma}(p)| \frac{(n+p)}{(n-p)}
\end{aligned}
$$

The AIC and FPE criteria asymptotically overestimates the order with positive probability, whereas the BIC and HQ criteria estimate the order consistently under fairly general conditions if the true order $\mathrm{p}$ is less than or equal to $p \max$.

\section{Results and Discussion}

Summary statistics of the Terrorism, Tourism and GDP growth are shown in Table 1. As it can be seen from Table 1, GDP growth has mean, median, maximum, minimum, standard deviation, skewness, kurtosis and Jarque-Bera of 2466.022, 1010.750, 11532.10, 17.60, 3236.846, 1.368595, 3.643677, and 43.48591 respectively for the period examined. The TERROR has a mean of 63.11364, median of 0.5 , maximum of 821 , minimum of 0.00 , standard deviation of 164.7157, skewness of 3.207575, kurtosis of 12.91129 and Jarque-Bera of 766.6325. Also, the descriptive statistics of TOUR has the following; mean of 166784.2, median of 151329.5, maximum of 485938.0, minimum off 13045.00, standard deviation of 109244.6, skewness of 0.671131, kurtosis of 2.825235, and Jarque-Bera 10.07717.

Taking into consideration, the probability value of the variables, it can be deduced that the p-value $(0.00<0.05)$ suggests non-normality for the three variables at $5 \%$ level of significance. Figure 1, 2, and 3 present the time series plot of Tourism, Terrorism and GDP growth.

Table 1: Summary Statistics

\begin{tabular}{|l|c|c|c|}
\hline & GDP & TERROR & TOUR \\
\hline Mean & 2466.022 & 63.11364 & 166784.2 \\
\hline Median & 1010.750 & 0.500000 & 151329.5 \\
\hline Maximum & 11532.10 & 821.0000 & 485938.0 \\
\hline Minimum & 17.60000 & 0.000000 & 13045.00 \\
\hline Std. Dev. & 3236.846 & 164.7157 & 109244.6 \\
\hline Skewness & 1.368595 & 3.207575 & 0.671131 \\
\hline Kurtosis & 3.643677 & 12.91129 & 2.825235 \\
\hline Jarque-Bera & 43.48591 & 766.6325 & 10.07717 \\
\hline Probability & 0.000000 & 0.000000 & 0.006483 \\
\hline
\end{tabular}




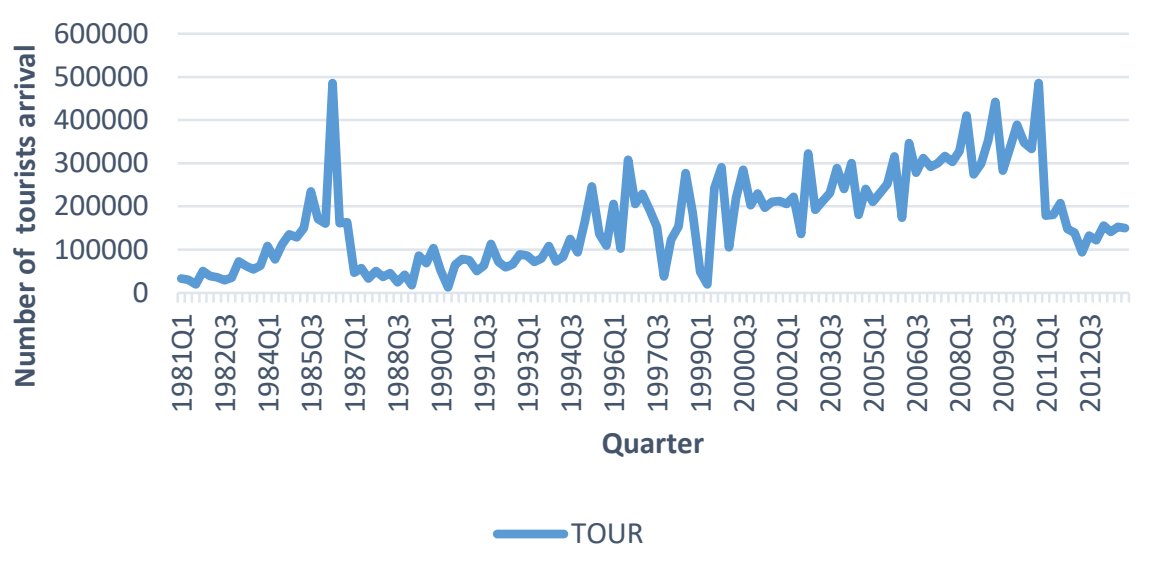

Figure 1. Time Plot of tourists' arrival into Nigeria for the period 1981Q1 to 2013Q4

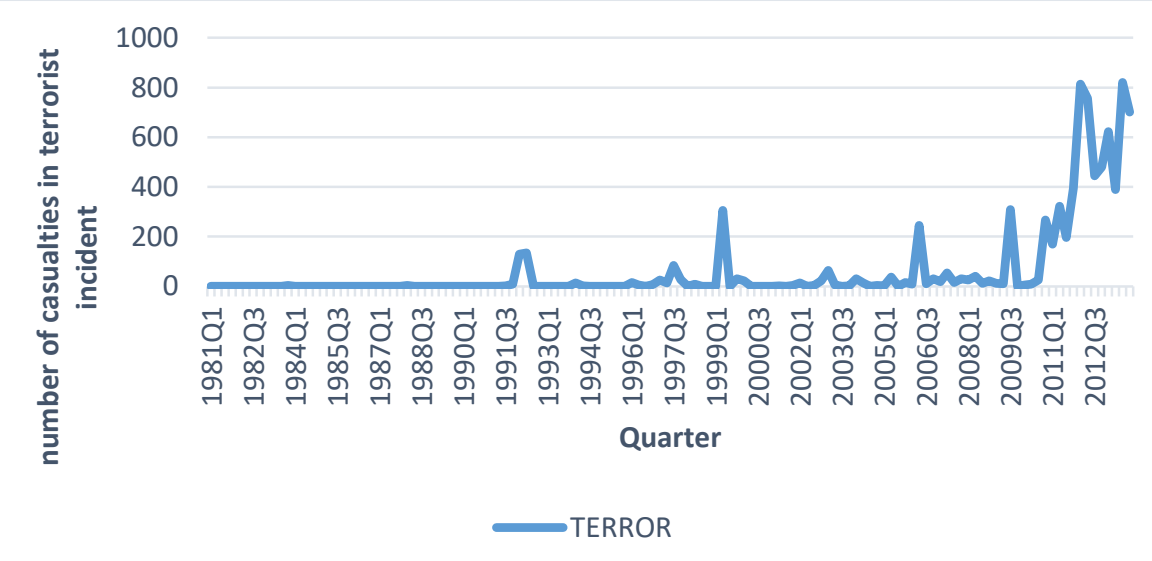

Figure 2. Time Plot of terrorists' arrival into Nigeria for the period 1981Q1 to 2013Q4 
Terrorism, Tourism and Economic Growth: Vector Autoregression (VAR) Analysis

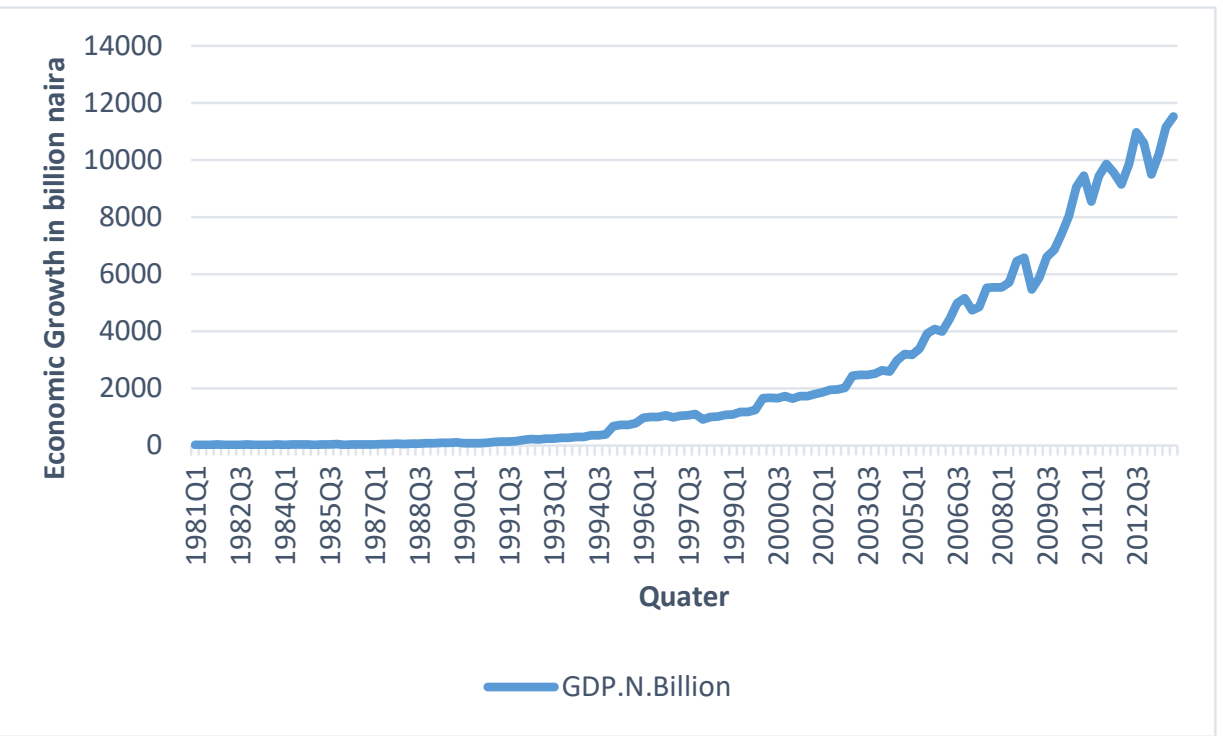

Figure 3. Time Plot of GDP for the period 1981Q1 to 2013Q4

Figure 1 shows a cyclic up-and-down behavior. The cycles do not repeat at regular intervals and do not have the same shape. Figure 2 suggests that the constant terrorist attacks are pretty flat in the previous years. But in the recent years, starting from 2010Q3, there was increase in the number of attacks which seems to be accelerating over time. As observed from Figure 3, there was a slight curve in the data, because the increase in the data values seems to accelerate over time as well.

\subsection{Unit Root Test}

I first formally test the stationarity of the time series variables and determine their order of integration, using the augmented Dickey - Fuller (Dickey \& Fuller, 1979) test. The results of the unit root tests are reported in Table 2. As can be seen, the three variables are integrated of order $0, I(0)$. Hence, the series are stationary at $5 \%$ level of significance

Table 2: Phillip-Peron Unit Root Test

\begin{tabular}{|c|c|c|c|c|}
\hline Variable & $\tau(\mathrm{PP})$ & $\mathrm{p}$-value & Decision & Remark \\
\hline GDP & -5.3976 & 0.0091 & Reject $\boldsymbol{H}_{\mathbf{0}}$ & $\mathrm{I}(0)$ \\
\hline TOUR & -6.4506 & 0.0073 & Reject $\boldsymbol{H}_{\mathbf{0}}$ & $\mathrm{I}(0)$ \\
\hline TERROR & -2.8402 & 0.0227 & Reject $\boldsymbol{H}_{\mathbf{0}}$ & $\mathrm{I}(0)$ \\
\hline
\end{tabular}


Note: $H_{0}: \emptyset=0$ ( there is unit root in the series) vs $H_{a}: \emptyset<0$ ( the series are stationary)

\subsection{Lag Length}

Table 3 presents the model selection criteria. The lag order chosen is 6 . Because the residuals of the VAR model are not correlated at this length.

Table 3: VAR Lag Order Selection

\begin{tabular}{|l|l|l|l|}
\hline AIC(n) & HQ(n) & SC(n) & FPE(n) \\
\hline 6 & 3 & 1 & 6 \\
\hline
\end{tabular}

\subsection{Results of VAR Test for Serial Correlation and ARCH Effect}

The results of VAR test for serial correlation and ARCH effect are presented in Table 3 . The result shows that the null hypothesis $H_{0}$ of no serial autocorrelation will not be rejected for portmanteau Test (Asymptotic), Breusch-Godfrey LM test since their $\mathrm{p}$-values are greater than the significance value of 0.05 for the $5 \%$ significant level. However, it will be rejected in ARCH LM Test indicating the presence of conditional heteroscedasticity since the p-value is less than the significance value of 0.05 for the $5 \%$ significant value.

Table 4. VAR Test for Serial Correlation and ARCH Effect

\begin{tabular}{|c|c|c|c|c|}
\hline Test & Chi-square & df & p-value & Decision \\
\hline $\begin{array}{c}\text { Portmanteau } \\
\text { test(Asymptotic) }\end{array}$ & 73.812 & 90 & 0.892 & Do not reject $\boldsymbol{H}_{\mathbf{0}}$ \\
\hline Breusch-Godfrey LM Test & 69.141 & 63 & 0.5204 & Do not reject $\boldsymbol{H}_{\mathbf{0}}$ \\
\hline ARCH LM Test & 270.62 & 180 & $1.433 \mathrm{e}-05$ & Reject $\boldsymbol{H}_{\mathbf{0}}$ \\
\hline
\end{tabular}

Note: Hypotheses Testing

$H^{1}{ }_{0}$ :There is no serial autocorrelation vs $H_{a}^{1}$ : There is serial autocorrelation $H^{2}{ }_{0}$ : There is no ARCH effect vs $H_{a}^{2}$ : There is ARCH effect 
Terrorism, Tourism and Economic Growth: Vector Autoregression (VAR) Analysis

\subsection{CUSUM Test for stability}

The cumulative sum (CUSUM) of recursive residuals test are applied to assess the parameter stability (Pesaran \& Pesaran, 1997). The cumulative sum test identifies systematic changes in the regression coefficients. Figure 4 plots the results for CUSUM test. The results indicate the absence of any instability of the coefficients because the plots of the CUSUM statistics fall inside the critical bands of the 5\% confidence intervals of parameter stability. Therefore, there exists stability in the coefficients over the sample period for the three variables.

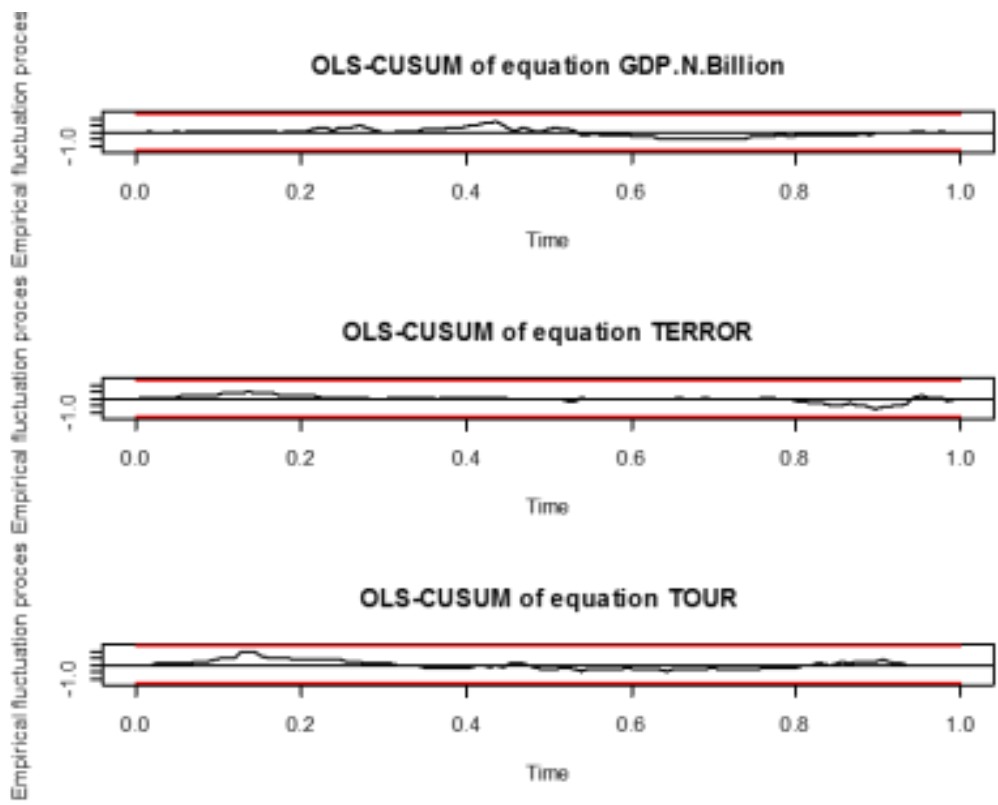

Figure 4. Plots of Residuals CUSUM

\subsection{Impulse Response Function}

Figure 5, presents the orthogonal impulse response function used to analyze the response of the dependent variables in the system to shocks from itself and the other explanatory variables. If the system of equations is stable, any shock should decline to zero; an unstable system would produce an explosive time path. Panel (a) of Figure 5 showed the impulse response of GDP to TOUR. When the impulse is GDP, the response of TOUR has an obvious fluctuation in a decreasing manner over the period with no tendency of dying out. The reason for this huge fluctuation was due to the increase in the number of terrorist attacks. From panel (b), the response of GDP period shock from GDP is initially positive and significant with a decrease pattern up to the 15 quarter. However, the effect of the shock from the 16 quarter has a smooth fluctuation with a negative decrease downward with no pattern 
of dying out. As depicted in panel (c), when the impulse is TOUR, the response of TOUR has an obvious fluctuation; the initial effect shows a decrease positive up to the 15 quarter and seems to die out within the quarter $16-19$. But from 20 quarter, the effect became significant with a negative smooth fluctuation with no evidence of die out. Panel (d) showed the response of TERROR to a shock from GDP. When an innovation is given to GDP, the terrorism responds positively to the system. Also, when there is one standard deviation positive shock in TOUR, TERROR react to the system negatively in the initials quarter and become positive after $11^{\text {th }}$ quarter. In panel (f), the response of TERROR to a shock from TERROR is positive and significant with an obvious fluctuation. This continues to decrease towards the end of the period with no tendency to die out. From panel (g), when the impulse is TERROR, the response of TOUR has an obvious fluctuation, there is a higher positive effect on the 6 quarter, lowest negative on the 2 quarter and the effect is almost significantly negative. The response of GDP to a shock from TOUR as depicted in panel (h) which is initially negative and significant up to 4 quarter but from 5 quarter, the effect became positive significant up to the 28 quarter with no tendency of die out pattern. When the impulse is TERROR, the response of GDP has an obvious fluctuation with negative effects with no tendency to die out apart from the 5 quarter which has a positive effect.

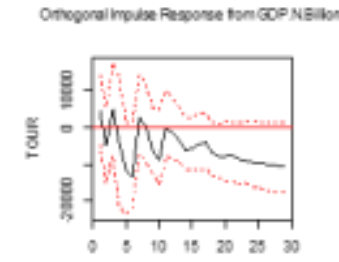

$2 a$
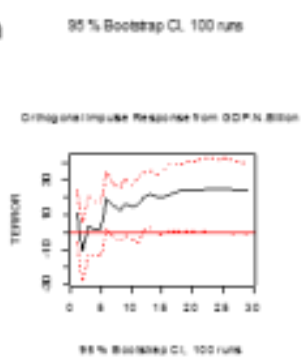

$2 \mathrm{~d}$

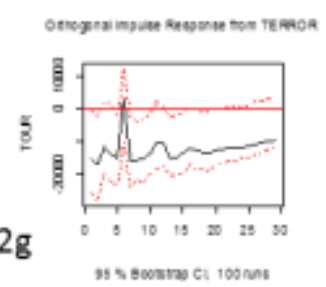

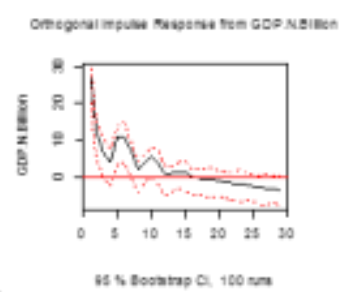

$2 b$
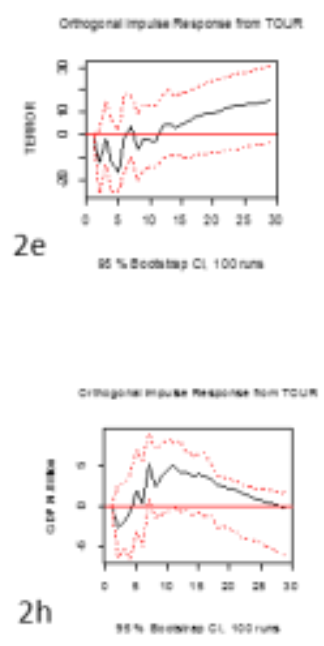

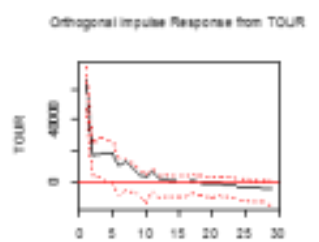

$2 \mathrm{c}$
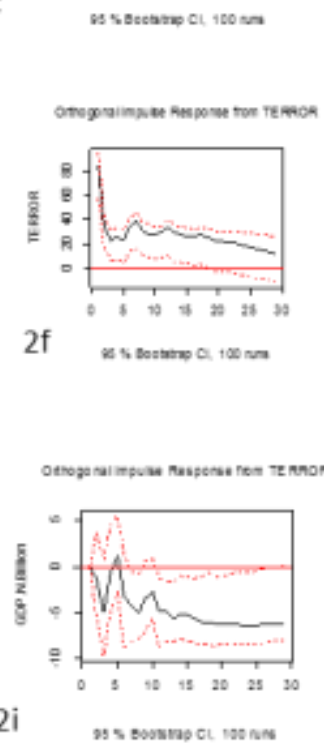

Figure 5. Orthogonal Impulse Response Functions 


\section{Conclusion and Policy Recommendations}

The objective of this study was to investigate the dynamics of interrelationships between/among Terrorism, Tourism, and GDP growth in Nigeria by using time series data for the period 1981Q1 - 2013Q4 obtained from Nigeria Bureau of Statistics (NBS), Global Terrorism Database (GTD) and World Tourism Organization (WTO) websites. At 5\% level of significance, Phillip-Perron unit root test shows that the three variables were found to be stationary at level. With confirmation that the variables were not co-integrated, a standard VAR (6) was chosen based on Akaike and FPE criteria. The CUSUM-test indicate the absence of any instability of the coefficients because the plots of the CUSUM statistics fall inside the critical bands of the 5\% confidence intervals of parameter stability. Therefore, there exists stability in the coefficients over the sample period for the three variables. Furthermore, the Impulse Response Functions, (IRFs) indicated that when one standard deviation positive innovation is given to terrorism, the tourism reacts negatively to the system. And an innovation into terrorism tends to decrease in economic growth. Also, when a standard deviation positive shock is given to tourism, terrorism responds negatively with an obvious fluctuation up to the $11^{\text {th }}$ quarter and continues in persistence manner with no trend of dying down. Thus, there is an urgent need for the government to stop the activities of the terrorists if Nigeria is to promote her GDP growth through international tourist arrivals because there was a negative impact of terrorism activities on GDP growth.

\section{References}

1. Abraham, P. and Mansfield, Y. (1996). Tourism, crime and international security. New York; John Wiley and Sons.

2. Adam, B. and Sinclair, M.T. (2002). Tourism crisis management adjusting to temporary downturn.

3. Adeniran, T. (1996). Terrorism and National Security. A Paper Presented in the Series of Staff Seminars of the Department of Political Science. University of Ibadan, April 5. 1996

4. Adibe, C. (1995). Managing Arms in Peace Process, Somalia: United Nations, New York and Geneva. Mixon. Press Ketu.

5. Adora, C. U. (2010). Managing tourism in Nigeria; The security option. Escanada Journal of Management Science and Engineering, 4(1), 14-21.

6. Afolabi, T. (2012). Harnessing Tourism Potentials for Sustainable Development: A Case of Owu Water Falls in Nigeria. Journal of Sustainable Development in Africa, 14(1), 121 - 125.

7. Ashley, C. and Mitchell, J. (2006). Can Tourism Help Reduce Poverty in Africa? Overseas Development Institute (ODI), Briefing Paper, ODI: London. 
8. Balaguer, L. and Cantavella, M. (2002). Tourism as a long-run economic growth factor: the Spanish case. Applied Economics, 34, 877-884.

9. Barash, D. and Webel, C. (2002). Peace and Conflict Studies. London: Sage Publications.

10. Bhagwati, J. (1998). The Capital Myth: The Difference between Trade in widget and Dallars. Foreign Affairs, May/ June.

11. Bhata, A. K. (2002). International Tourism Management. New Delhi. Sterling Publisher Ltd.

12. Durbarry, R. (2002). The economic contribution of tourism in Mauritius. Annals of Tourism Research, 29(3), 862-5.

13. Emmanuel, A. A. (2007). Tourism and Recreation. An unpublished URP 511 Lecture note for the Department of Urban and Regional Planning, Federal University of Technology Akure.

14. Enders, W. and Sandler, T. (2006). The impact of Transnational Terrorism on U.S. Foreign Direct Investment. Political Research Quarterly 59(4), 517-531.

15. Essner, J. (2003) Terrorism's impact on Tourism; What the industry may learn from Egypt'sstruggle with al-Gama al-islamiya.

16. Harmon, C. (2000). Terrorism Today. (2nd ed.). London. Mill house Press.

17. Helpman, E. and Krugman, P. (1985). Market structure and foreign trade. MIT Press, Cambridge.

18. Holloway, J. (2001). The Business of Tourism. Edinburg. Pearson Educational Limited.

19. http://www.worldtourism.org/newsroom/releases/2003/September/wtd.htn

20. Iyiola, O. and Oni-Ojo, E. E. (2013). Attitudes toward service innovations in red meat industry and its consumption effects on Nigerian consumers. Developing Country Studies, 3(9), 39- 49.

21. Khalil, S., Kakar, M. and Waliullah, K. (2007). Role of Tourism in Economic Growth: Empirical Evidence from Pakistan Economy. Applied Economics Research Centre, University of Karachi.

22. Lacker, J. (2004). Payment System Disruptions and the Federal Reserve Following September11, 2001, Paper Prepared for the Carnegie-Rochester Conference on Public Policy, November 21-22, 2003.

23. Lee, C. C. and Chang, C. (2008). Tourism development and economic growth: a closer look at panels. Tourism Management, 29, 180-192.

24. McKinnon, R. I. (1964). Foreign exchange constrains in economic development and efficient aidallocation. Economic Journal, 74, 388-409.

25. Middleton, V. T. C. and Hawkins, R. (1998). Sustainable tourism: A marketing perspective. UK: Butter Worth-Heinemann, 134-139, 148-152.

26. Mir, L. A. (2014). An economic evaluation of Indian Tourism Industry, International Research Journal, 4(12). 
Terrorism, Tourism and Economic Growth: Vector Autoregression (VAR) Analysis

27. Sackett, H. and Botteril, D. (2006). Perception of International Travel Risk: An Exploratory Study of the influence of Proximity to Terrorist Attack. E-review of Tourism Research, 4(2), 44-49.

28. Telce, Y. H. and Schroenn, J. L. (2006). The Contribution of HRD to TourismLed Development in an African Context. South Africa Journal of Economics and Management Sciences, 4, 444-457.

29. The Economist (2005). The Lost Trail: Efforts to Combat the Financing of Terrorism Are Costly and Effective, Seminar. (October 22, 2005).

30. Tourism. (2008). Wikipedia Free Online Encyclopedia 2008. Retrieve on March 28, 2008, from http://en.wikipedia.org/wiki/ Tourism.html.

31. TTC (2013). Reducing Barriers to Economic Growth and Job Creation. The Travel and Tourism Competitiveness Report.

32. Weber, S. (1998). War, Terrorism and Tourism. Annals of Tourism Research, 25(3), 760-763.

33. World Tourism Organization (2003) WTO, Highlight tourism vital role in global plan for poverty alleviation.

34. WTO. (2009). Available from http://www.worldtourism.org/facts/menu.html [Accessed January 2010].

35. WTTC (2014, 2015). World Travel and Tourism Council, $2014 \&$ 2015. The Authority on World Travel and Tourism: Travel and Tourism Economic Impact on Nigeria.

36. Zortuk, M. 2009. Economic impact of tourism on Turkey's economy: evidence from co-integration tests. International Research Journal of Finance and Economics, 25, 231-239. 